\title{
Correction to: The Pharmacist Guide to Implementing Pharmaceutical Care
}

Filipa Alves da Costa, J. W. Foppe van Mil and Aldo Alvarez-Risco

\section{Correction to:}

F. Alves da Costa et al. (eds.), The Pharmacist Guide

to Implementing Pharmaceutical Care, https://doi.org/10.1007/978-3-319-92576-9

The original version of the book was published with the affiliation "Ordem dos Farmacêuticos (Portuguese Pharmaceutical Society), Lisbon, Portugal" of the editor, Professor "Filipa Alves da Costa" in the frontmatter and in chapters 5, 14, 35, 37 and 38, which has now been changed to "Instituto Universitário Egas Moniz (IUEM), Monte da Caparica, Portugal”.

The updated online version of these chapters can be found at https://doi.org/10.1007/978-3-319-92576-9_5

https://doi.org/10.1007/978-3-319-92576-9_14

https://doi.org/10.1007/978-3-319-92576-9_35

https://doi.org/10.1007/978-3-319-92576-9_37

https://doi.org/10.1007/978-3-319-92576-9_38

https://doi.org/10.1007/978-3-319-92576-9 